\title{
Contribuições freireanas para a contextualização no ensino de Química
}

Juliana Cardoso Coelho1

Carlos Alberto Marques2

\begin{abstract}
Resumo: Ao se investigar o ensino de Química em escolas situadas na região de mineração do carvão em Criciúma (SC), argumenta-se sobre a necessidade de um trabalho pedagógico mais amplo envolvendo as situações de contexto, para que haja uma aproximação dos temas químicos sociais ao referencial freireano e da Química Verde. A pesquisa foi desenvolvida com um grupo de professores em duas etapas: um questionário, que objetivou analisar a compreensão dos mesmos sobre as situações-problema cotidianas do contexto local e, em seguida, uma entrevista com professores, que foi precedida pela leitura de um texto que caracteriza aquele ambiente da mineração do carvão como área crítica nacional em termos de controle da poluição. A interpretação das entrevistas dos professores foi conduzida pela Análise Textual Discursiva e os resultados apontaram que não havia uma compreensão mais ampla da realidade que os cerca e de sua não utilização no ensino de Química. Há o predomínio de abordagens descontextualizadas e distantes das vivências e saberes dos alunos sobre o contexto em questão.
\end{abstract}

Palavras-chave: ensino de Química, contextualização, Química Verde.

\section{Freireanas contributions for the contextualization in teaching of Chemistry}

\begin{abstract}
A wider pedagogical work involving cases through the teaching of Chemistry in schools located in the areas of coal extraction has been proposed in order to find a closer relation between chemical issues to the "freiriano" referential and Green Chemistry. A new teaching plan for this subject is proposed. This research was developed in two stages through a questionnaire applied to a group of teachers that aimed to analyze the understanding of the difficulties found in their daily routine, followed by an interview. The following interview was preceded by the reading of a text that characterizes the coal mining as being a critical area, in terms of pollution. The interpretation of the teachers' understanding was conducted by the Textual Analysis and the results stated, showed that there was not a wide understanding of their surrounding reality and of its usage in the teaching of Chemistry. There is a domination of disconnected approaches and a distance between the students routine and knowledge about this subject.
\end{abstract}

Keywords: teaching of Chemistry, Contextualization, Green of Chemistry. 


\section{Introdução}

No contexto das pesquisas educacionais realizadas no Brasil e referentes ao ensino de Química em particular, cresce o número daquelas pesquisas que têm o propósito de superar um ensino distanciado do contexto local dos estudantes. Ensino esse baseado comumente no modelo de transmissão de conhecimentos e com fins memorísticos, que superdimensionam o ensino de conceitos em detrimento de outros objetivos educacionais mais ligados à formação científica para o exercício da cidadania (SANTOS; SCHNETZLER, 1997).

A evocação de mudanças nas práticas de ensino de Química justifica-se não somente por convicções de cunho ideológico, mas também por recentes orientações curriculares (BRASIL, 1999), além de um diagnóstico de desestruturação do ensino de Química até então praticado na maioria das escolas (SANTOS; SHNETZLER, 1997). Em contrapartida, a pesquisa supracitada situa-se num marco importante, por enfatizar a proposição de que o ensino de Química seja voltado à formação para o exercício da cidadania.

Nessa perspectiva, Chassot (1990) posiciona-se com propriedade ao destacar que, de modo geral, o que se encontra é um ensino de Química que pouco tem contribuído para a transformação dos estudantes em cidadãos críticos, a ponto de afirmar que, da forma como tem sido praticado, esse ensino resulta em algo literalmente "inútil", ou no paradoxo útil/inútil, realmente útil, para manter o status quo. À continuação, o autor argumenta a favor de um ensino de Química questionador que deve transformar-se, por consequiência, num ensino libertador. Em consonância com esse pensamento, educadores químicos entrevistados na pesquisa realizada por Santos e Schnetzler (1997) foram unânimes na indicação da inclusão de temas químicos sociais no conteúdo programático. Esses temas referem-se a assuntos relacionados ao conhecimento químico e que afetam diretamente a sociedade, a exemplo da "poluição". A meta é propiciar um ensino de Química voltado ao desenvolvimento do exercício da cidadania aos egressos do ensino médio. Nesse sentido, a contextualização social no ensino de Química tem sido defendida em vários trabalhos (SANTOS; SCHNETZLER, 1997) (SANTOS; MORTIMER, 1999a, b) como condição necessária ao objetivo educacional de formação da cidadania. Para tanto, os autores acima citados defendem a abordagem de aspectos sócio-científicos 
(ASC), caracterizados como questões ambientais, políticas, econômicas, éticas, sociais e culturais, referentes à ciência-tecnologia por meio de temas químicos sociais.

Como evolução dessas pesquisas, Mól e Santos (2005), em co-autoria com professores do ensino médio, elaboraram um livro didático estruturado por meio de temas sociais desenvolvidos por meio de textos que buscam estabelecer relações destes com o conteúdo químico, explorando a perspectiva dos aspectos ASC. Os limites dessa abordagem são analisados por Santos (2002), que considera que ainda é o conteúdo disciplinar da Química que estrutura e organiza a sequiência do livro. Além disso, também considera que a abordagem que o livro apresenta para os aspectos ASC não corresponde ao da proposta de Paulo Freire, dado que o tema não é extraído da vivência cultural dos estudantes. Santos destaca que apenas um número reduzido de questões solicita aos alunos uma reflexão acerca de problemas que possam encontrar em sua comunidade.

A defesa da abordagem contextualizada no ensino é bastante acentuada nos documentos oficiais da reforma curricular, como os PCN (BRASIL, 1999), que considera que o aprendizado necessita de exemplos relevantes, regionais ou locais. Assim sendo, o contexto dos estudantes, a sua vivência cotidiana, tem sido apontado como algo de suma importância para os processos de ensino-aprendizagem. Nesse caso, as orientações curriculares constituem um dispositivo oficial/legal que ampara o empreendimento de práticas pedagógicas condizentes com uma concepção transformadora de educação, em que se busca propiciar meios para que os estudantes, enquanto sujeitos históricos, compreendam o potencial que possuem como agentes de transformação social.

Sob tais aspectos, o presente artigo discute sobre a abordagem de temas químicos sociais a partir de contextos relevantes para os estudantes, pautando-se nos pressupostos freireanos de educação. O objetivo principal é discorrer, a partir da pesquisa realizada, como os processos e atividades de ensino-aprendizagem devem dar ênfase ao constante desvelamento da realidade (FREIRE, 1997a), com vistas a possibilitar, sobretudo, o desencadeamento de um processo de ação transformadora dessa mesma realidade pela interferência dos sujeitos na sociedade. Visa, portanto, contribuir com a estruturação de uma proposta teórico-metodológica que permita melhor organizar o planejamento de ensino-aprendizagem, ao se adotar a abordagem contextualizada no ensino de Química em direção à superação das lacunas a que nos referimos anteriormente 
levantadas por Santos (2002), ao se referir sobre temas químicos sociais e sobre a proposta freireana.

Nessa perspectiva, levando em consideração a vivência dos estudantes num contexto caracterizado pela mineração do carvão em Criciúma (SC), foram identificadas, por meio de um levantamento de dados, situações significativas, ou situações-problema, (DELIZOICOV, ANGOTTI, PERNAMBUCO, 2002) que surgem como manifestações da contradição existencial dos habitantes dessa região em particular. Numa prática freireana, tais situações apresentam-se como desafios não somente para melhor compreendê-las, mas também atuar para transformá-las, sendo a educação problematizadora algo de fundamental importância nesse intento. Exemplos de tais situações serão evidenciados a seguir quando se discute a realidade do contexto em questão.

\section{A relevância do contexto: a mineração como exemplo}

A gravidade dos problemas ocasionados ao meio ambiente pela mineração do carvão levou a região carbonífera sul-catarinense a ser designada, desde a década de oitenta do último século, como "área crítica brasileira, em termos de recuperação ambiental" (SCHEIBE, 2002). Atribui-se, como a causa principal à origem dos impactos ambientais ocorridos na região, o fator econômico fomentado por atores sociais ligados à atividade do carvão. A abrangência dos efeitos (pelo menos no tocante à poluição do solo, ar e água) ultrapassa a esfera local e regional, não possuindo fronteiras (CÔRREA, 2001).

Em Criciúma, principal cidade inserida no contexto da região carbonífera sulcatarinense, muitos dos problemas ambientais ocasionados pela mineração do carvão são extremamente visíveis ao se circular pelas rodovias do município, assim como os problemas de saúde a ela relacionados. No tocante à poluição das águas, o sistema hidrográfico da região é apontado como o mais degradado do Estado, devido ao aporte da poluição do carvão (SANTA CATARINA, 1991, 1997). Quanto à poluição atmosférica, segundo as estimativas feitas e apresentadas em documento oficial por ocasião da Rio-92 (SANTA CATARINA, 1991), os poluentes emitidos pelas indústrias ligadas ao setor carbonífero ultrapassam em muito os limites da legislação ambiental. Da mesma forma, o relatório faz menção aos resíduos sólidos das atividades da indústria carbonífera, que 
caracterizam outro foco de contaminação em cadeia do solo, ar e água, uma vez que foram dispostos a céu aberto ou aos cursos d'água sem qualquer tratamento. Ademais, há uma grande incidência de doenças respiratórias que são significativamente maiores que nas demais regiões do Estado, sendo 70\% das internações verificadas nos hospitais da região e $27 \%$ dos óbitos atribuídos a doenças ocasionadas pela poluição de atividades ligadas ao carvão (SANTA CATARINA, 1991).

Considerando ainda os problemas ocasionados aos seres humanos, destaca-se a grande incidência de pneumoconiose, definida pela medicina como doença ocupacional (SOUZA FILHO; ALICE; DE LUCA, 1981), produzida pela aspiração contínua e prolongada de poeiras que se acumulam nos pulmões, de evolução lenta e não regressiva, que geralmente leva à invalidez ou à morte precoce, e que deve, portanto, ser prevenida. Um estudo realizado entre os anos de 1969-79, constante na publicação de 1981, relata que foram diagnosticados 536 casos de pneumoconiose nos trabalhadores das minas de carvão (PTC). Os médicos-pesquisadores afirmam que o número de casos de PTC excede 3000 casos (SOUZA FILHO; ALICE, 1996).

$\mathrm{Na}$ origem dessas situações, nas quais se mesclam fatores de ordem social, política, econômica, entre outros, destaca-se o interesse de atores sociais ligados ao setor carbonífero que, na ânsia por lucro, não reconheceram os interesses da coletividade no panorama histórico de desenvolvimento regional. Segundo Santos (1995), foram conjunturas nacionais e internacionais que possibilitaram os ciclos de produção do carvão em Santa Catarina, como por exemplo, a $1^{\mathrm{a}}$ e $2^{\mathrm{a}}$ Guerras Mundiais e a crise do petróleo dos anos 70. O autor estende sua análise até a desregulamentação da atividade pela política neoliberal, ocorrida em 1990, que levou ao fechamento de muitas minas e ocasionou uma enorme taxa de desemprego na região, e esclarece que não havia interesse, por parte dos empresários do setor carbonífero, em investir numa atividade que só conseguia mercado consumidor em momentos de crise. Dessa forma, é possível compreender as razões pelas quais não ocorreram investimentos em tecnologias mais eficientes, que certamente resultariam num menor custo ao meio ambiente.

Para os estudantes dessa região, tais situações fazem parte do cotidiano, e os professores de Química da cidade de Criciúma, em particular, deveriam saber trabalhar 
aspectos dessa realidade em suas aulas. É para isso que deveria servir o ensino de Química e o enfoque temático contextualizado.

As questões anteriormente levantadas reforçam a compreensão que vai ao encontro da visão totalizada do contexto, argumentada por Freire (1997a) ao defender o contexto local dos educandos como ponto de partida para uma maior compreensão do mundo. É preciso lembrar que o autor recebeu muitas críticas por centrar o conhecimento em contextos locais, às quais revidou (FREIRE, 1997b) argumentando que jamais defendera uma posição reducionista "focalista":

Creio que o fundamental é deixar claro ou ir deixando claro aos educandos esta coisa óbvia: o regional emerge do local tal qual o nacional surge do regional e o continental do nacional como o mundial emerge do continental. Assim como é errado ficar aderido ao local, perdendo-se a visão do todo, errado é também pairar sobre o todo sem referência ao local de onde se veio. (FREIRE, 1997b, p. 87-88).

Cumpre ainda notar que na configuração do quadro descrito foram negligenciados aspectos preventivos, e as investidas nocivas contra o meio ambiente ainda hoje afligem toda a região. Tais aspectos, no que se refere à poluição e sob a ótica da Química Verde - QV (ANASTAS; WILLIAMSON, 1996), têm sido alvo de debate entre os pesquisadores no momento atual.

\section{O meio ambiente, um contexto de crises: um olhar a partir dos princípios}

\section{da Química Verde.}

Os problemas de poluição, resultantes da utilização indiscriminada do carvão mineral, que afetam a cidade de Criciúma e parte daquela região catarinense, podem ser inseridos na discussão da caracterizada crise ambiental de nossos tempos. Essa problemática tem gerado crescentes interrogações, a nível mundial, devido ao cenário preocupante e ao desafio que resulta o seu enfrentamento (TIEZZI, 1998). Corrêa (2001) assinala que somente após a Conferência Mundial de Meio Ambiente de 1972, realizada em Estocolmo, o Brasil passou a adotar uma política nacional para o meio ambiente. Como destaca o autor, até então o Estado estava às voltas com a necessidade de crescimento econômico, legitimando agressões ao meio ambiente tal como ocorreu com o 
intenso protecionismo dado à atividade de mineração do carvão. Assim, a incessante destruição do meio ambiente parece ter ocorrido com respaldo direto ou indireto do poder público, em nome de uma política desenvolvimentista.

É nesse panorama atual de graves problemas ambientais que a QV vem se consolidando como um campo de pesquisa e influenciando a maneira de refletir acerca das atividades químicas e dos impactos de poluição ambiental causados por aquelas atividades. Nesse modelo proposto está inserida a necessidade de uma prática química que, mediante uma postura ética, aja de modo a antecipar os problemas de poluição no meio ambiente, isto é, que atue preventivamente, resgatando a máxima de que é melhor prevenir do que remediar, pois quanto menos se prevenir maior será a necessidade de monitoramento e saneamento dos poluentes emitidos, que nem sempre resolvem satisfatoriamente o problema.

Portanto, a preocupação central está em superar a mera eficiência "técnica", na maioria das vezes assumida como neutra, e a eficácia econômica dos processos químicos, considerando que os processos que geram poluição possam ser substituídos por alternativas menos poluentes ou não poluentes. Nesse sentido, norteiam a QV doze princípios fundamentais, dos quais se destaca a prevenção (ou redução na fonte) como o modo mais eficiente para evitar ou minimizar os problemas de poluição no meio ambiente (ANASTAS; WILLIAMSON, 1996).

Em recente publicação, Humeres e colaboradores (2004) divulgaram estudos empreendidos sobre os mecanismos da dessulfurização dos gases efluentes da combustão do carvão, processo que gera o sulfeto de carbono, que possui aplicação industrial, e que evita, dessa forma, maiores prejuízos ao meio ambiente - uma forma de prevenção defendida pela QV. Não obstante, tal processo não pode ser reduzido a uma questão técnica: "um grande número de processos têm sido propostos para remover o dióxido de enxofre de gases de exaustão, mas poucos têm alcançado escala comercial" (HUMERES et al., 2004, p. 320). Assim, aponta-se sobretudo para o princípio da prevenção, mas com a ressalva de que é necessário superar a visão unilateral do "aspecto técnico". Segundo Pacey (1990), a maioria das pessoas identifica e se atém a esse aspecto, caracterizado, entre outros, pelo conhecimento de como fazer as coisas funcionarem, englobando nessa esfera o conhecimento químico. O termo "técnica", e não tecnologia, é sugerido pelo 
autor como sendo o mais indicado, uma vez que a compreensão da "prática tecnológica" envolve, além do aspecto técnico, o organizacional e cultural, este último incorporando os objetivos e os valores envolvidos. Logo, no caso da mineração do carvão da região sulcatarinense, se considerássemos um componente físico-químico do meio, ou seja, a pirita como a "grande vilã" da história (SHEIBE, 2002), permaneceríamos presos a uma abordagem eminentemente "técnica" (PACEY, 1990), cogitando soluções para os problemas que assolam a região de forma eficiente. Por sua vez, a concepção progressista de educação se empenha na problematização da realidade percebida de forma ingênua.

Dessa forma, pelos aspectos levantados, parece-nos que a pirita não deve ser responsabilizada, de forma valorativamente neutra, pelos impactos ambientais na região. Conforme destacado, deve-se considerar a interferência de atores sociais que desconsideraram outros métodos e técnicas mais eficientes para a exploração, beneficiamento e armazenamento do carvão.

O enfoque no "aspecto técnico" gera passividade e torna as pessoas alheias ao que realmente é pertinente considerar: a interferência dos cidadãos na sociedade pela participação pública nos processos decisórios referentes a temas envolvendo ciênciatecnologia, que é algo postulado pelo emergente enfoque Ciência-Tecnologia-Sociedade (CTS) no contexto da educação nacional (AULER; BAZZO, 2001) (SANTOS; MORTIMER, 2000) (SANTOS, 2006).

Busca-se, portanto, a participação social numa perspectiva de ensino CTS para que tecnologias preventivas balizadas pelos princípios da QV se configurem no cenário das indústrias químicas, incluindo a carbonífera. Percebe-se, assim, o papel que o ensino de Química pode e deve desempenhar na formação de pessoas que tenham conhecimentos necessários para se posicionarem com propriedade frente às situações problemáticas do seu contexto, seja regional ou local.

\section{Reflexões teórico-metodológicas a partir do referencial freireano}

O contexto local encerra a contradição do desenvolvimento econômico regional em contrapartida aos prejuízos ocasionados ao meio ambiente. Para Paulo Freire, as diferentes contradições expressam aspectos problemáticos presentes na estrutura social e 
que têm fortes determinantes econômicos. Estas precisam ser compreendidas criticamente pelos "educandos-educadores" visando, sobretudo, contribuir no processo de libertação humana.

Em relação ao ensino de Química, atualmente existem pesquisas sob a temática da educação para a cidadania e que têm como principal objetivo preparar o cidadão para o mundo científico-tecnológico (SANTOS; SCHNETZLER, 1997; SANTOS; MORTIMER, 2002). Entre as fundamentais contribuições proporcionadas por essas pesquisas para os educadores químicos, destaca-se o clamor feito à necessidade de mudanças no ensino de Química, no sentido de que nos processos de ensinoaprendizagem sejam introduzidos "temas químicos sociais", com vistas a estabelecer uma relação entre o conhecimento químico com problemas de relevância para a sociedade e a romper com a visão hegemônica de uma pretensa neutralidade do conhecimento químico e de seu ensino.

A proposta dos temas químicos sociais tem sido desenvolvida pelo grupo inserido no Projeto Ensino de Química e Sociedade - PEQUIS, por meio do livro didático "Química e Sociedade" (SANTOS; MÓL e colaboradores, 2005), que se encontra circulando no mercado e ainda de fácil acesso aos professores da área. Nesse material, a abordagem do conhecimento químico é feita em base nos aspectos sócio-científicos, ou seja, questões ambientais, políticas, econômicas, éticas, culturais, sociais, envolvidos nos temas relacionados à ciência-tecnologia, entre os quais, poluição atmosférica, aqüífera, uso de agrotóxicos, etc.

Todavia, na origem da indicação dos temas químico-sociais, ou somente temas sociais, encontra-se uma comunidade de educadores químicos. Nesse caso, inegavelmente, há ausência dos alunos na construção programática, seja pela ausência de sua "voz" no processo seja pelo fato de que, eventualmente, tais temas não contemplem fatos, eventos e palavras que possuam significado para os mesmos. Ou, dito de outro modo, não foram extraídos de seu contexto local.

Portanto, aponta-se para a necessidade de uma exploração intensa do contexto, isto é, das "situações significativas". Em nossa investigação levantamos essas situações e identificamos um tema ambiental, a poluição, numa região onde esses problemas são mais evidentes. A discussão foi fundamentada, sobretudo, no referencial freireano, da QV e do 
enfoque CTS. A partir de algumas evidências de nossa pesquisa, acreditamos que existe a possibilidade de que, se alguns caminhos metodológicos forem percorridos, poderá haver uma aproximação entre a proposta da contextualização por meio dos temas químicos sociais e a da educação transformadora proposta por Freire.

Logo, percorrendo a perspectiva freiriana "[...] os temas geradores identificados durante a investigação temática, contêm as contradições, e delas são manifestações [...]" (DELIZOICOV, D., 2003, p. 134) e envolvem "situações significativas"1 do contexto da comunidade na qual a escola se insere. Tal processo possui algumas diferenças daquele proposto pelos temas químicos sociais, que foram sugeridos por um grupo de professores que, entre outras qualificações, atuam na formação inicial e continuada de professores de Química.

Parte-se do pressuposto de que a contextualização se constitui num instrumento teórico e princípio curricular de fundamental importância para o empreendimento de uma educação que se enquadre na perspectiva transformadora.

Nessa ótica, Ricardo (2005) argumenta a favor da contextualização que se concretiza no momento em que o ponto de partida é a "realidade imediata", à qual se retorna com possibilidades de intervenção, uma vez que se dispõe de conhecimento para tal. O autor diferencia essa perspectiva daquela em que não há o retorno a "essa realidade", sendo que o fim se constitui nos conceitos científicos. Ou ainda o contrário, ou seja, partir do abstrato para o concreto, de modo que a contextualização sirva mais como ilustração de fatos do cotidiano em vez de ser utilizada como um instrumento para uma melhor compreensão do mundo.

Os resultados de algumas pesquisas, em particular no ensino de Química, também apontam para uma tendência dos professores associarem a contextualização como o ensino de Ciências relacionado ao cotidiano, ou seja, a uma prática que se limita à descrição científica de fatos e processos que ocorrem no dia-a-dia dos estudantes e também como uma estratégia de ensino para facilitar a aprendizagem (SANTOS; MORTIMER, 1999a,b). Sustentados no referencial CTS, os autores diferenciam esse tratamento da contextualização no ensino, que tem por objetivo preparar os estudantes

\footnotetext{
${ }^{1}$ Identificadas no levantamento preliminar: primeira etapa da investigação temática (FREIRE, 1997a).
} 
para o exercício da cidadania. Nessa perspectiva, o foco principal consiste na formação de pessoas capazes de agir e tomar decisões sobre problemas de importância social.

De fato, nossa pesquisa em Criciúma (COELHO, 2005) constatou o predomínio do "distanciamento das situações-problema cotidianas" evidenciado pelo ensino de conceitos científicos puramente relacionados seja às substâncias e às exemplificações do dia-a-dia, à realização de atividades experimentais com materiais do cotidiano, ou às ilustrações de substâncias químicas nos produtos industrializados e de uso diário. De modo que apontamos para a predominância de práticas pedagógicas descontextualizadas no ensino de Química, considerando a vivência dos estudantes no contexto de mineração do carvão.

O objeto principal da pesquisa consistiu em investigar a "percepção crítica da realidade", em particular de problemas ambientais, de um grupo de professores de Química de Criciúma (SC). Assim, utilizando categorias teórico-metodológicas freirenas, buscou-se conhecer a "consciência real" (ou efetiva) e a "consciência máxima possível" (Freire, 1997a) desses professores acerca do contexto em que atuam e de sua utilização no ensino de Química (COELHO; MARQUES, 2007).

Num primeiro momento, quinze professores responderam um questionário, que proporcionou indícios de práticas de ensino em termos de um distanciamento do que chamamos "situações-problema cotidianas". A partir disso, realizaram-se entrevistas semi-estruturadas com sete professores do grupo que respondeu o questionário, quando se utilizou um texto que aborda a região sul do Estado como área crítica nacional em termos de controle de poluição. O distanciamento das situações problema cotidianas foi bastante evidenciado na etapa subseqüente da pesquisa onde, frente ao contexto apresentado pelo texto anteriormente citado, apenas um professor se aproximou de uma abordagem da poluição enquanto problema socialmente relevante, ao contrário dos outros seis docentes que concederam a entrevista.

O contato com os profissionais ocorreu durante cinco meses, de junho a outubro de 2004, divididos em dois momentos: primeiro, a aplicação de um questionário; em seguida, uma entrevista semi-estruturada.

Dada a quase ausência absoluta de manifestações sobre questões de ordem social, política e econômica que caracterizaram o contexto local (COELHO, 2005), foi 
possível afirmar que não havia, por parte dos professores de Química entrevistados, uma compreensão mais ampla das "situações significativas" desse contexto, estando, por isso, distantes de uma "conscientização" (FREIRE, 1980) da realidade que os cerca. Permanecem, portanto, "imersos" ou ainda no nível da "consciência real" (FREIRE, 1997a) onde, segundo Freire (1997a), ocorrem limitações de perceber o "inédito viável" que está mais além do que denominou "situações-limite".

Aquilo que se entende por conscientização “[...] é o olhar crítico da realidade, que a 'desvela' para conhecê-la e para conhecer melhor os mitos que enganam e ajudam a manter a realidade dominante.” (FREIRE, 1980, p. 29). Ela é relevante por também favorecer a participação e o compromisso social do coletivo educacional, e que não pode evidentemente ser empreendida por uma concepção "bancária" de educação (FREIRE, 1997a).

Para Freire, a educação bancária é estimulante da ingenuidade e da não criticidade, e enfatiza a permanência; já a educação transformadora reforça a mudança, é de caráter crítico, reflexivo e estimula um pensar autêntico. Enquanto a primeira pretende manter a "imersão", a segunda busca a "emersão das consciências" que resulte numa "inserção crítica na realidade", num "constante ato de desvelamento da realidade". Portanto, toda ação educativa, como ato político (FREIRE, 1997a, b), é de primordial importância.

Centrando-se especificamente no ensino de Química, não obstante o caráter interdisciplinar da prática freireana (SÃO PAULO, 1989a, 1989b, 1992), é possível compreender que esta ciência, ao proporcionar conhecimentos, pode contribuir para uma melhor compreensão de contextos significativos. Nesse sentido, não é somente a escola que vai dar conta das grandes mudanças que precisam ocorrer no âmago da estrutura social. Todavia, a escola não pode se eximir de dar a sua contribuição, a exemplo da pesquisa desenvolvida pelos médicos-pesquisadores da região carbonífera sul-catarinense (SOUZA FILHO; ALICE; DE LUCA, 1981, 1991).

\footnotetext{
1 Freire considera as "situações-limite" como realidades objetivas que provocam necessidades nos indivíduos. No contexto de nossa pesquisa, foram consideradas "situações-limite": programas de ensino fragmentados e sobrecarregados de conceitos; falta de material didático adequado para planejamento das aulas; formação do professor; falta de tempo para planejamento das aulas; salários entre outras.
} 
$\mathrm{Na}$ consideração do tratamento do tema "poluição", através da disciplina de Química, é importante salientar que na prática freireana há atuação do coletivo educacional em torno da implementação de uma proposta, envolvendo um projeto político pedagógico que não se restringe à escola; necessita-se de vontade política. Além do mais, considera-se de fundamental importância a participação de professores das diferentes áreas do conhecimento, dado que: “[...] é como se o fenômeno ou situação fossem vistos através de uma lente que os decompõe segundo as diferentes luzes do conhecimento (física, química, biologia, história, geografia, artes etc), permitindo revelar aspectos fragmentados da realidade [...] (DELIZOICOV, D.; ZANETIC, 1993, p. 13).

Contudo, Freire (1997a) também aponta para a necessidade da utilização do "tema-dobradiça", pela evidência deste tema no contexto dos estudantes, não havendo necessariamente, neste caso, as cinco etapas da "investigação temática" das quais se obtêm os temas geradores:

[...] A introdução destes temas, de necessidade comprovada, corresponde, inclusive, à dialogicidade da educação, de que tanto temos falado. Se a programação educativa é dialógica, isto significa o direito que também têm os educadores-educandos de participar dela, incluindo temas não sugeridos. A estes, por sua função, chamamos "temasdobradiças". (FREIRE, 1997a, p. 136, grifo nosso).

Dessa forma, considerando a identificação das "situações significativas" da comunidade local (COELHO, 2005), estamos desenvolvendo uma pesquisa ${ }^{1}$ com o objetivo de compreender como os professores podem instituir um processo de discussão com os alunos de modo que ambos possam identificar "situações significativas" do contexto em que vivem. Assim, mesmo se partindo de um tema escolhido previamente pela comunidade de professores de Química, a saber, um "tema químico social”, seria possível edificá-lo como um "tema-dobradiça", na perspectiva freireana, o que viria a aproximar ainda mais a proposta metodológica da contextualização por meio dos temas químicos sociais e aquela defendida por Freire. Isso poderia contribuir e auxiliar os professores de Química na organização de um processo pedagógico, com estratégias de ensino-aprendizagem dialógico-problematizadoras.

\footnotetext{
${ }^{1}$ Pesquisa desenvolvida no âmbito do doutorado de Juliana Cardoso Coelho, sob a orientação do professor Dr. Carlos Alberto Marques (PPECT/UFSC).
} 
Contextos significativos, como o da região de Criciúma, precisam ser compreendidos, sendo de primordial importância propor, tanto aos professores quanto aos estudantes, o "desvelar" crítico dessa realidade, no sentido de uma ação transformadora.

\section{Considerações finais}

Em nosso país existem contradições que, apesar de emergirem de contextos específicos, estão interligadas a uma realidade que é global, e necessitam ser investigadas e desveladas criticamente, se o ideário for investir na perspectiva de uma educação transformadora.

É legítimo aventar a possibilidade de que os estudantes brasileiros estejam em grande parte ainda "imersos" na realidade que vivenciam; e isso na medida em que é inegável a influência de uma educação calcada no "depósito" do conhecimento. Além disso, também há as ideologias que, de acordo com Auler (2002), "ainda não morreram", bem como o agravante de nossa herança colonial, conforme salientam autores como Auler e Bazzo (2001) ao considerarem as condições para inserção do enfoque CTS no Brasil.

Para enfrentar e superar contradições sociais faz-se necessário ousar no constante ato de "desvelar" a realidade, o que possibilita a evolução da "consciência máxima possível". Nesse intuito, a contextualização constitui-se como algo de suma importância para discutir, juntamente com professores e estudantes, o potencial que estes possuem como agentes transformadores da sociedade, de modo que é preciso auxiliar os professores de Química a vislumbrarem o potencial oferecido por esse instrumento teórico para leitura crítica de mundo (FREIRE, 1997a, b).

Nessa perspectiva, um ensino de Química voltado à cidadania, do qual se parte da proposição de um tema social para a contextualização do conteúdo, poderia se aproximar ainda mais da proposta de contextualização de Paulo Freire. Mas isto se os professores estivessem aptos a desvelar situações significativas da comunidade em que atuam, o que favoreceria o empreendimento de um ensino de Química transformador de contradições sociais. 


\section{Referências bibliográficas:}

ANASTAS, P.T.; WILLIAMSON, T.C. Green chemistry: an overview. In: Green chemistry: designing chemistry for the environment. Washington, DC, American Chemical Society, p.1-17, 1996.

AULER, D. Interações entre Ciência-Tecnologia-Sociedade no contexto da formação de professores de Ciências. 2002. Tese (Doutorado em Educação)-Centro de Ciências da Educação da Universidade Federal de Santa Catarina, Florianópolis, 2002.

AULER, D.; BAZZO, W.A. Reflexões para a implementação do movimento CTS no contexto educacional brasileiro. Ciência \& Educação, São Paulo, v.7, n. 1, p.1-13, 2001.

BRASIL. Ministério da Educação e do Desporto. Secretaria de Ensino Médio e Tecnológico. Parâmetros Curriculares Nacionais: ensino médio. Brasília, 1999.

CHASSOT, A. I. A educação no ensino da Química. Ijuí: INIJUÍ, 1990.

COELHO, J. C. A chuva ácida na perspectiva de tema social: um estudo com professores de Química em Criciúma (SC). Dissertação (Mestrado em Educação Científica e Tecnológica)- Centro de Centro de Ciências Físicas e Matemáticas, Centro de Ciências da Educação, Centro de Ciências Biológicas da Universidade Federal de Santa Catarina, Florianópolis, 2005.

; MARQUES, C.A. A chuva ácida na perspectiva de tema social: um estudo com professores de Química. Química Nova na Escola, São Paulo, n. 25, p.14-19, 2007.

CORRÊA, J. Proteção ambiental e atividade mineraria: um estudo de caso sobre a defesa da área de proteção ambiental dos morros Estevão e Albino, no Município de Criciúma. 2001. Dissertação (Mestrado em Direito)-Centro de Ciências Jurídicas da Universidade Federal de Santa Catarina, Florianópolis, 2001.

DELIZOICOV D. Práticas freirianas no ensino de ciências. In: CAUÊ, Matos (Org.). Conhecimento e vida Cotidiana. São Paulo: Terceira Margem, 2003.

; ANGOTTI, J. A.; PERNAMBUCO, M. M. Ensino de Ciências: fundamentos e métodos. São Paulo: Cortez, 2002.

; ZANETIC, J. A proposta de interdisciplinaridade e o seu impacto no Ensino Municipal de $1^{o}$ grau. In: PONTUSCHKA, Nídia Nacib (Org.).Ousadia no diálogo Interdisciplinaridade na escola pública. São Paulo: Edições Loyola, 1993.

FREIRE, P. Pedagogia do oprimido. 24. ed. Rio de Janeiro: Paz e Terra, 1997a.

Pedagogia da esperança: um reencontro com a pedagogia do oprimido. 4. ed. Rio de Janeiro: Paz e Terra, 1997b. 
Conscientização: teoria e prática da libertação: uma introdução ao pensamento de Paulo Freire. 3 ed. São Paulo: Cortez e Moraes, 1980.

HUMERES E.; MOREIRA, R.F. P. M; PERUCH, M.G.B. O Enxofre como poluente: remoção de dióxido de enxofre de efluentes gasosos. In: TUNDO, P.; ROSSI, R. H. (Ed.).Química verde en Latinoamérica. Argentina: IUPAC/INCA, 2004 (Green Chemistry Series, 11).

RICARDO, E. Competências, interdisciplinaridade e contextualização: dos parâmetros curriculares nacionais a uma compreensão para o ensino das ciências. 2005. Tese (Doutorado em Educação)- Centro de Centro de Ciências Físicas e Matemáticas, Centro de Ciências da Educação, Centro de Ciências Biológicas da Universidade Federal de Santa Catarina, Florianópolis, 2005.

PACEY, A. La cultura de la tecnología. México: Fondo de Cultura Económica, 1990.

SANTA CATARINA. Secretaria de Estado da Tecnologia, Energia e Meio Ambiente. Fundação do Meio Ambiente. Santa Catarina - 92: perfil ambiental e estratégias. Florianópolis, 1991.

Secretaria de Estado do Desenvolvimento Urbano e Meio ambiente. Bacias Hidrográficas de Santa Catarina: diagnóstico geral. Florianópolis, 1997.

SANTOS, M. A. Crescimento e crise na região sul de Santa Catarina. 1995. Dissertação (Mestrado)-Centro de Filosofia e Ciências Humanas da Universidade Federal de Santa Catarina, Florianópolis, 1995.

SANTOS, W.L.P. Aspectos sociocientíficos em aulas de Química. 2002. Tese (Doutorado em Educação)-Faculdade de Educação da Universidade Federal de Minas Gerais, Belo Horizonte, 2002.

SANTOS, W.L.P. Letramento em Química, Educação Planetária e Inclusão Social. Química Nova, São Paulo, v.29, n. 3, p.611-620, 2006.

\begin{tabular}{ccc}
; Mol, G.S. (coord) e colaboradores. Química e Sociedade. Volume único. Nova \\
\hline Geração: & São & Paulo,
\end{tabular}

SANTOS, W. L. P.; SCHNETZLER, R. P. Educação em Química: compromisso com a cidadania. Ijuí: INIJUÍ, 1997.

; MORTIMER, E. F. Concepções de professores sobre contextualização social do ensino de Química e Ciências. In: REUNIÃO ANUAL DA SOCIEDADE BRASILEIRA DE QUÍMICA, 22., 1999a. Poços de Caldas, MG.,1999a. v.3, ED. 070. Livro de Resumos.

A Dimensão social do ensino de Química: um estudo exploratório da visão de professores. In: ENCONTRO NACIONAL DE PESQUISA E ENSINO DE 
CIÊNCIAS, 2., 1999b, Valinhos, SP. Anais... Valinhos, SP: [s.n.], 1999b. Atas. 1 CDROM.

.Uma análise de pressupostos teóricos da abordagem CTS (CiênciaTecnologia-Sociedade) no contexto da educação brasileira. Ensaio: Pesquisa em Educação em Ciências, Belo Horizonte, v. 2, n. 2, p. 133-162, 2000.

SÃO PAULO, Secretaria Municipal de Educação. Ação Pedagógica na Escola pela via da Interdisciplinaridade. São Paulo. Cadernos 1,2 e 3. 1989a.

. Movimento de reorientação Curricular. São Paulo. Documentos 1 e 2. 1989 b.

1992.. Movimento de reorientação Curricular - Ciências: Visão de Área. São Paulo.

SCHEIBE, L. F. O Carvão de Santa Catarina: mineração e conseqüências ambientais. In:

TEIXEIRA, E. C.; PIRES, M. J. R. (Coord.). Meio Ambiente e Carvão: impactos da Exploração e Utilização. Porto Alegre,RS: PADCT/GTM, 2002. (Cadernos de Planejamento e Gestão Ambiental, 2). p. 45-63.

TIEZZI, E. Tempos históricos, tempos biológicos: a terra ou a morte: problemas da "nova ecologia". Tradução de Frank Roy Cintra Ferreira, Luiz Eduardo de Lima Brandão, São Paulo: Nobel, 1998.

SOUZA FILHO, A. J.; ALICE, H. S.; DE LUCA, V. Pneumoconiose dos trabalhadores das minas de carvão. Jornal de Pneumologia, [S.1.], v. 7, n. 2, p.57-66, jun.1981.

Fibrose maciça pulmonar progressiva. Jornal de Pneumologia, [S.1], v. 17, n.4, p. 147-153, dez. 1991.

Pneumoconiose dos trabalhadores do carvão. In: VIEIRA, Sebastião Ivone (Coord.). Medicina Básica do Trabalho. 2. ed. Curitiba: Gênesis, v.2, 1996. 